
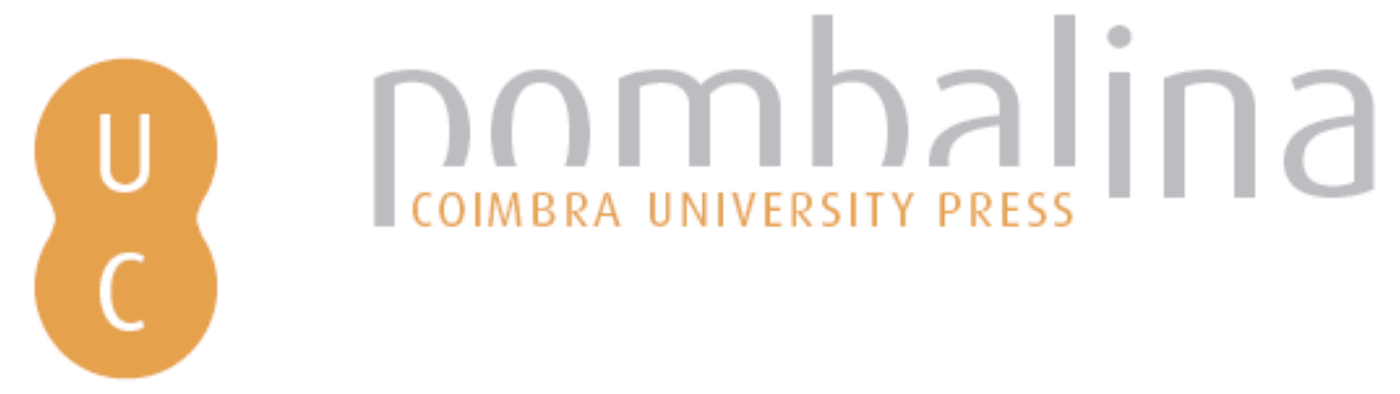

\title{
Sono normal e problemas do sono
}

Autor(es): $\quad$ Madureira, Núria; Estevão, Maria Helena

Publicado por: Imprensa da Universidade de Coimbra

URL

persistente: URI:http://hdl.handle.net/10316.2/43114

DOI: $\quad$ DOI:https://doi.org/10.14195/978-989-26-1300-0_13

Accessed : $\quad$ 26-Apr-2023 12:43:43

A navegação consulta e descarregamento dos títulos inseridos nas Bibliotecas Digitais UC Digitalis, UC Pombalina e UC Impactum, pressupõem a aceitação plena e sem reservas dos Termos e Condições de Uso destas Bibliotecas Digitais, disponíveis em https://digitalis.uc.pt/pt-pt/termos.

Conforme exposto nos referidos Termos e Condições de Uso, o descarregamento de títulos de acesso restrito requer uma licença válida de autorização devendo o utilizador aceder ao(s) documento(s) a partir de um endereço de IP da instituição detentora da supramencionada licença.

Ao utilizador é apenas permitido o descarregamento para uso pessoal, pelo que o emprego do(s) título(s) descarregado(s) para outro fim, designadamente comercial, carece de autorização do respetivo autor ou editor da obra.

Na medida em que todas as obras da UC Digitalis se encontram protegidas pelo Código do Direito de Autor e Direitos Conexos e demais legislação aplicável, toda a cópia, parcial ou total, deste documento, nos casos em que é legalmente admitida, deverá conter ou fazer-se acompanhar por este aviso.

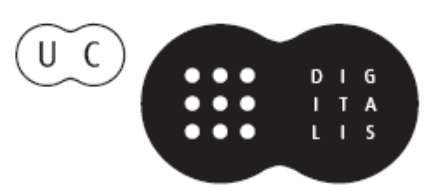


Capítulo 13.

Sono normal

e problemas do sono
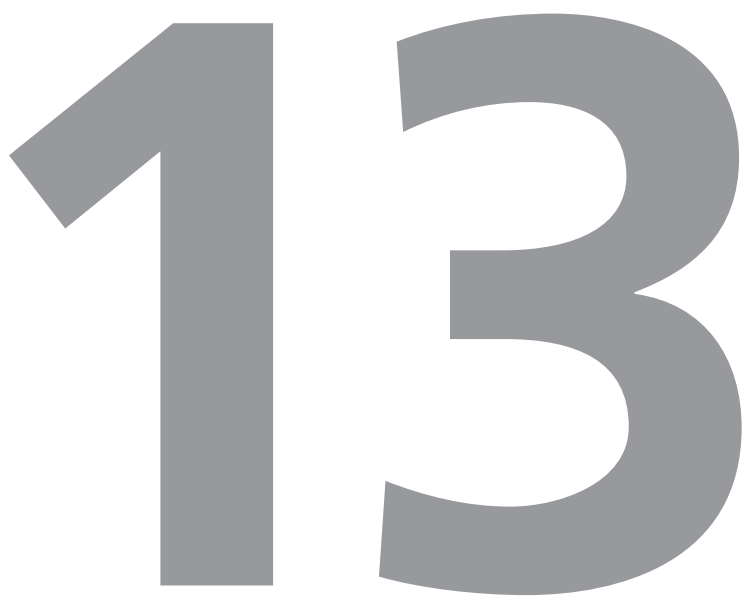

Núria Madureira

e Maria Helena Estevão 


\subsection{CONTEXTO}

O sono é um estadio comportamental caraterizado pela ausência de interação e resposta ao meio ambiente, com diminuição da atividade motora e reversível com estimulação. É fundamental no restabelecimento de vários sistemas orgânicos, conservação da energia, manutenção da termoregulação e imunidade e em determinadas funções endócrinas como a produção de hormona do crescimento. Desempenha um papel importante nas funções cognitivas como a consolidação da memória, e no crescimento e desenvolvimento do sistema nervoso central.

\subsection{DESCRIÇÃO DO TEMA}

O ciclo sono-vigília é regulado por dois processos que funcionam em conjunto. O processo homeostático regula a duração e a profundidade do sono e está relacionado com a acumulação de substâncias químicas promotoras de sono durante a vigília. O ritmo circadiano endógeno influencia o horário e a duração do ciclo sono-vigília e depende da produção de melatonina regulada pela alternância claridade-escuridão.

A arquitetura do sono baseia-se no reconhecimento de que existem duas fases distintas: Non-rapid eye movement (NREM) e Rapid eye movement (REM):

- NREM - corresponde à fase de sono profundo ou reparador, com baixa atividade cerebral, frequências cardíacas e respiratórias mais baixas e regulares, diminuição da temperatura corporal e com diminuição relativa do tónus muscular mantendo alguma capacidade de movimento;

- REM - refere-se à fase de sono com intensa atividade cerebral (com sonhos), movimentos oculares rápidos, ausência da termorregulação e de tónus muscular (exceto no diafragma e nos músculos dos olhos e do ouvido médio).

Durante a noite, as duas fases alternam-se em ciclos com uma duração de 90 a 110 minutos cada. Estes ciclos terminam em breves microdespertares e repetem-se quatro a seis vezes por noite. A proporção das diferentes fases em cada ciclo varia durante a noite, com o sono NREM predominando no primeiro 1/3 e o sono REM no último terço da noite, figura 1.

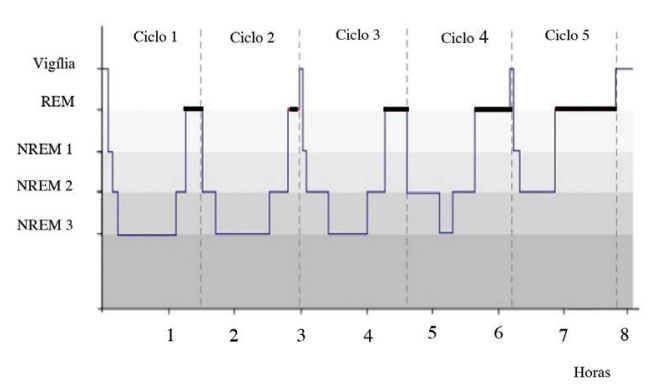

Figura 1 - Hipnograma mostrando ciclos e fases do sono.

A arquitetura do sono varia com a idade. Nos primeiros dois meses de vida não existem os padrões electroencefalográficos que permitem distinguir as fases do sono, pelo que este se divide em três estadios: ativo (equivalente ao REM), calmo (equivalente ao NREM) e indeterminado. Durante o primeiro ano de vida, individualizam-se 
as fases de sono REM e NREM, durando os ciclos de sono cerca de 50 minutos. Estes ciclos vão-se tornando mais longos à medida que a criança cresce, até atingir os 90 a 110 minutos. Com o crescimento a duração total de sono nas 24 horas vai diminuindo bem como a proporção de sono REM e inversamente há um aumento de sono NREM.

No quadro 1 descrevem-se as principais caraterísticas do sono em função da idade.

Durante o primeiro ano de vida é fundamental estabelecer medidas de higiene do sono. O primeiro passo é garantir adequada educação parenteral nas consultas de vigilância de saúde infantil e juvenil. Os horários de sono devem ser regulares e adequados à idade da criança, respeitando a variabilidade individual. As sestas devem também ser adaptadas à idade e ao desenvolvimento da criança e, quando já só há uma sesta, esta deve ser realizada no início da tarde e durar no máximo duas horas. Antes de dormir devem ser evitadas bebidas estimulantes, refeições pesadas ou exercício físico. A rotina de ir para a cama deve ser consistente, de curta duração e com atividades calmas e agradáveis. O ambiente em que se dorme também é importante, não devendo existir televisão, computador ou telémovel no quarto.

\begin{tabular}{|c|c|}
\hline Idade & Sono \\
\hline 0 - 2 meses & $\begin{array}{l}\text { Duração de sono - } 10 \text { a } 19 \text { / } 24 \text { horas. } \\
\text { Períodos de sono alternados com uma a duas horas de vigília, determinados pela fome } \\
\text { e saciedade e sem padrão diurno/noturno. } \\
\text { Padrões de sono irregulares. }\end{array}$ \\
\hline 2 - 12 meses & $\begin{array}{l}\text { Duração de sono - } 12 \text { a } 13 \text { / } 24 \text { horas. } \\
\text { Período de sono noturno de nove a dez horas. Diminuição progressiva do número de } \\
\text { sestas diurnas, de quatro a duas. } \\
\text { Desenvolve-se a capacidade de adormecer sozinho. }\end{array}$ \\
\hline $1-3$ anos & $\begin{array}{l}\text { Duração de sono - } 11 \text { a } 13 \text { / } 24 \text { horas. } \\
\text { Passa a haver apenas uma sesta durante o dia (habitualmente por volta dos } 18 \text { meses). }\end{array}$ \\
\hline $3-6$ anos & $\begin{array}{l}\text { Duração de sono - } 9 \text { a } 10 / 24 \text { horas. } \\
\text { Em idade variável desaparecem as sestas. Cerca de } 26 \% \text { das crianças de quatro anos } \\
\text { e } 15 \% \text { das de cinco anos necessita de sesta. }\end{array}$ \\
\hline $6-12$ anos & Duração de sono - 9 a $10 / 24$ horas. \\
\hline Adolescência & $\begin{array}{l}\text { Duração de sono - } 8 \text { a } 9 \text { / } 24 \text { horas. } \\
\text { Com a puberdade há um atraso fisiológico na produção da melatonina que condiciona } \\
\text { o início do sono cerca de duas horas mais tarde do que é habitual. Os adolescentes } \\
\text { têm tendência a estar mais alerta à noite e a acordar mais tarde. }\end{array}$ \\
\hline
\end{tabular}

Quadro 1. Características do sono em função da idade. 


\section{Distúrbios do sono}

Estima-se que cerca de $30 \%$ das crianças/ adolescentes apresente ou já tenha apresentado algum problema de sono, quadro 2. A falta de identificação e orientação pode contribuir para a sua persistência até à idade adulta. É fundamental que estas situações sejam diagnosticadas e orientadas atempadamente e, por isso, o inquérito de hábitos do sono deve fazer parte das consultas de vigilância de saúde infantil e juvenil. Devem ser abordadas questões relativas à hora de deitar e de levantar (durante a semana e fim-de-semana), rotina de ir dormir, resistência em ir para a cama, dificuldade em adormecer e despertares noturnos; sintomas noturnos como ressonar, pausas respiratórias, agitação ou movimentos exuberantes, episódios de confusão, choro ou deambulação; sintomas diurnos como a sonolência excessiva, hiperatividade, perturbações do comportamento ou dificuldades de aprendizagem.

Higiene inadequada do sono

Parassónias

Insónias

Hipersónias

Distúrbios do ritmo circadiano

Perturbações respiratórias do sono

Distúrbios do movimento relacionados

com o sono

Sono nas doenças médicas

Quadro 2. Principais grupos de problemas do sono em idade pediátrica.

\section{Parassónias}

As parassónias são fenómenos aberrantes do sono, reflexo da imaturidade cerebral. A sua prevalência diminui com a idade, todavia podem persistir até à idade adulta.

Nas parassónias da fase NREM existe uma perturbação do mecanismo do despertar caraterizada por uma diferente ativação sono-vigília em diferentes áreas corticais. A criança/adolescente está a dormir mas tem comportamentos motores ou autonómicos da vigília. Atendendo às características do sono NREM, compreende-se que estes episódios sejam mais frequentes na primeira metade da noite e que não haja memória para o episódio. A história familiar é frequentemente positiva já que existe uma predisposição genética. A esta associam-se fatores precipitantes que condicionam a ocorrência e frequência dos episódios: privação, má higiene ou simplesmente alteração do padrão de sono (como dormir num local diferente); alterações emocionais ou comportamentais e patologias como o síndrome de apneia obstrutiva do sono.

Os diferentes tipos de parassónias do NREM são:

1. Sonambulismo (entre os quatro e os 12 anos) - episódios de comportamentos motores complexos com deambulação, podendo a criança falar ou responder a ordens e ter vagas memórias do episódio;

2. Terrores noturnos (entre os três e os oito anos) - ocorrências de fenómenos de início súbito, com graus variados de atividade motora e sinais autonómicos de medo intenso (taquicardia, taquipneia, rubor facial, sudorese e midríase); a criança apresenta um fácies de susto, está confusa, agitada, chora ou grita, não manifesta o que a perturba, não acalma 


\begin{tabular}{|l|l|l|}
\hline Características & Terrores noturnos & Pesadelos \\
\hline Horário noturno & Primeiro terço da noite & Último terço da noite \\
\hline Fase do sono & NREM & REM \\
\hline Limiar para despertar & $\begin{array}{l}\text { Elevado, as crianças estão a } \\
\text { dormir profundamente }\end{array}$ & Baixo, as crianças acordam \\
\hline Resposta ao consolo & $\begin{array}{l}\text { Não } \\
\text { A intervenção parenteral pode } \\
\text { mesmo prolongar os episódios }\end{array}$ & $\begin{array}{l}\text { Sim } \\
\text { As crianças têm necessidade de ser } \\
\text { tranquilizadas para voltar a dormir }\end{array}$ \\
\hline Memória para o episódio & Nenhuma ou fragmentada & Vivida \\
\hline
\end{tabular}

Quadro 3. Diagnóstico diferencial entre as parassónias, terrores noturnos e pesadelos.

com a presença dos pais e após alguns minutos continua a dormir;

3. Despertares confusionais (entre os seis meses e os sete anos) - fenómenos de início lento e duração mais prolongada, em que não há alterações comportamentais, respostas autonómicas ou componente motor relevante; a criança tem um ar assustado, com olhar vago e um discurso confuso e lentificado.

Na abordagem das parassónias do NREM é importante tratar fatores precipitantes e tranquilizar a família, explicando que a única intervenção deve ser garantir a segurança e que a criança/adolescente não deve ser acordado. Se as características não forem típicas (vários episódios por noite, horário não habitual, movimentos estereotipados, posturas distónicas ou memória lúcida para o episódio) deve ser equacionado o diagnóstico diferencial com crises epiléticas.

As parassónias do período REM mais frequentes são os pesadelos. Ocorrem na segunda metade da noite, há memória para o episódio, e as crianças acordam completamente, estando assustadas e com medo de voltar a dormir. Nestes casos é importante tranquilizar e transmitir segurança. Os pesadelos são frequentemente confundidos com terrores noturnos, as características que os distinguem são apresentadas no quadro 3.

\section{Insónias}

A insónia define-se como a dificuldade no início do sono, na sua consolidação ou qualidade. Pode surgir em qualquer idade e ter múltiplos fatores desencadeantes.

Nos primeiros anos de vida, importa destacar a insónia comportamental da infância, em que há uma perturbação do funcionamento diário da criança ou da família associada ao problema de sono.

No subtipo sleep-onset association, a criança (seis meses a três anos) tem dificuldade em adormecer sozinha e apresenta múltiplos despertares durante a noite. A partir dos seis meses, os lactentes têm capacidade para adormecer sozinhos. Se aprenderem a adormecer em determinadas condições (como, por exemplo, 
Sonolência excessiva diurna

Privação ou perturbação do sono

- Má higiene de sono

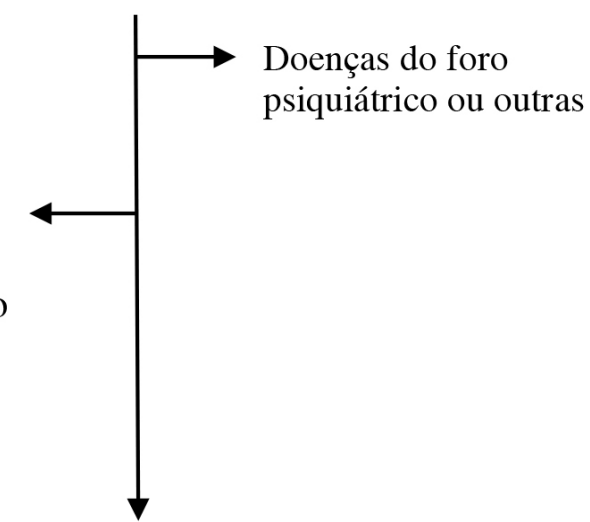

Hipersónia verdadeira

Figura 2. Diagnóstico diferencial de sonolência excessiva diurna no adolescente.

a mamar ou a serem embalados), continuarão a necessitar delas nos vários microdespertares que ocorrem no final dos ciclos de sono normais. Na sua ausência, vão acordar e chorar ou chamar pelos pais.

No subtipo limit setting type, a criança (mais de dois anos) resiste em ir para a cama tornando a rotina de adormecer prolongada e com múltiplos pedidos. Se acordar durante a noite chama pelos pais ou vai ter com eles à cama. Na base da resistência em ir dormir podem estar fatores como os medos, a ausência de regras ou a inadequação dos horários de sono.

Existe também um subtipo misto em que estão presentes características de ambos. Na abordagem da insónia comportamental da infância é fundamental explicar aos pais a fisiopatologia da situação e estabelecer estratégias de terapia comportamental adequadas à criança e à família.
A resistência em ir dormir ou a dificuldade em adormecer podem também ser consequência de expetativas parenterais inadequadas relativamente ao sono do seu filho. A criança pode ter uma necessidade em dormir inferior à que os pais consideram ou ter uma preferência circadiana pela noite. Ao ser forçada a ir dormir numa altura em que não tem sono, resiste ou tem dificuldade em adormecer. Devem também ser excluídas doenças como doença de refluxo gastroesofágico, eczema atópico, doenças neurológicas ou outros distúrbios do sono.

\section{Hipersónia}

A hipersónia é um sintoma que ocorre com maior frequência no adolescente. O primeiro passo na sua abordagem é compreender se a sonolência excessiva diurna está relacionada com sono noturno insuficiente ou perturbado ou se se deve a uma hipersónia verdadeira. A abordagem da sonolência excessiva diurna encontra-se esquematizada na figura 2 . 


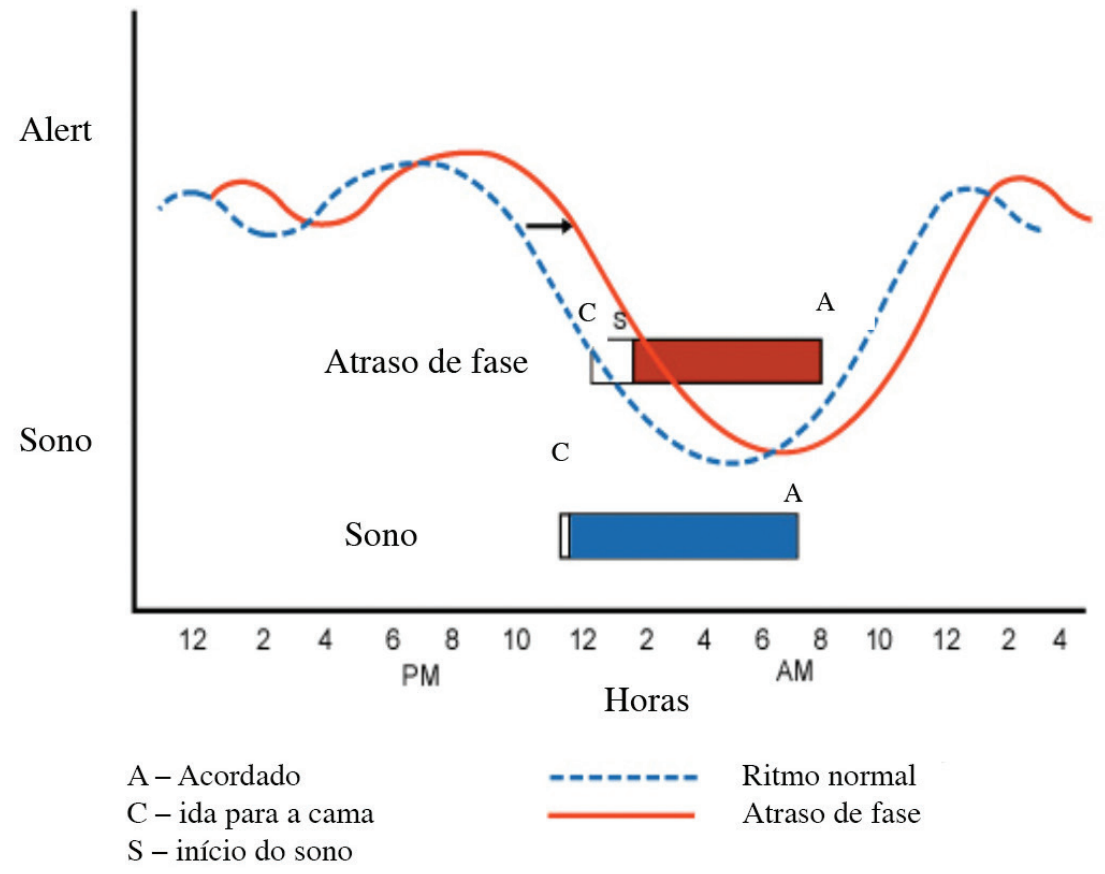

Figura 3. Atraso de fase de sono característico do adolescente.

Devem ser excluídas doenças que cursem com dor ou necessidade de tomar medicação durante a noite, psiquiátricas (como a depressão) e distúrbios do sono como a perturbação respiratória obstrutiva do sono ou o síndrome de pernas inquietas. A privação de sono pode também estar relacionada com má higiene do sono - horários irregulares, horário tardio de ir dormir e/ou presença e uso de televisão, computador ou telemóvel.

O síndrome de atraso de fase é um distúrbio do ritmo circadiano que causa insónia e sonolência excessiva diurna na adolescência. A sua etiologia ainda não é completamente conhecida. Parece haver uma anomalia na regulação do ciclo sono-vigília, endógena e/ou condicionada por fatores ambientais, e que está relacionada com atraso na produção da melatonina que ocorre na puberdade. Tipicamente estes adolescentes adormecem tarde e se for possível acordam tarde, sendo, nestas circunstâncias, a duração de sono normal. Clinicamente há insónia inicial (quando o adolescente tenta adormecer a uma hora socialmente aceitável mas que não corresponde à altura em que tem sono) e dificuldade em acordar de manhã (se tiver que ser num horário não desejado) podendo condicionar absentismo escolar, sonolência diurna excessiva com sestas durante o dia, dificuldades escolares e perturbações comportamentais ou do humor. No tratamento do síndrome de atraso de fase é fundamental a motivação do adolescente e da família e podem ser utilizados ajustes de horários de ir dormir e acordar, exposição à luz ou administração de melatonina, figura 3. 
Na hipersónia verdadeira existe uma diminuição da capacidade de alerta, com sonolência excessiva diurna e sono noturno prolongado. São situações raras, cujo exemplo é a narcolepsia. A narcolepsia é uma perturbação crónica do SNC com desregulação do ciclo sono-vigília e intrusão do sono REM na vigília. Manifesta-se habitualmente na segunda década de vida, mas pode surgir mais cedo. A etiologia é desconhecida, sendo o mecanismo fisiopatológico mais provável a destruição autoimune de células do hipotálamo produtoras de hipocretina, em indivíduos com suscetibilidade genética (presença do alelo HLA DQB1*06:02). Clinicamente há sonolência excessiva diurna e, frequentemente mais tarde, cataplexia, alucinações hipnagógicas (ao adormecer) ou hipnopômpicas (ao acordar) e paralisia do sono. A cataplexia, paradigmática da narcolepsia, é uma redução súbita e reversível do tónus muscular, desencadeada por um estímulo como a gargalhada ou o susto. Pode haver dificuldades de aprendizagem, perturbações do comportamento ou do humor. Nas crianças, é difícil equacionar a hipótese de narcolepsia, já que pode apenas existir sonolência excessiva diurna, e esta ser interpretada como necessidade fisiológica de sesta ou preguiça da criança. O diagnóstico assenta na realização de um estudo poligráfico do sono para excluir outras causas de sonolência, e de um teste de latência múltipla do sono em que se avalia o grau de sonolência diurna e a ocorrência no início do sono da fase REM. É efetuada também a pesquisa do HLA DQB1*06:02 que está presente em $90 \%$ dos casos mas é inespecífico. Pode ser necessário efetuar o doseamento da hipocretina-1 no líquido cefalorraquidiano, que está diminuída. Do tratamento fazem parte estratégias de terapia comportamental e fármacos para controlar a sonolência (como o metilfenidato) e a cataplexia (como a venlafaxina).

\section{Perturbação respiratória \\ obstrutiva do sono}

\section{Na perturbação respiratória obstrutiva}

do sono existe uma diminuição da patência da via aérea superior que, em conjunto com a hipotonia muscular do sono, condiciona um aumento da resistência à entrada do fluxo aéreo. Em idade pediátrica, os fatores de risco mais frequentes são a hipertrofia adenoamigdalina (causa principal), a obesidade, a prematuridade, as malformações craniofaciais ou os dismorfismos faciais minor, a rinite alérgica, a laringomalácia e o refluxo-gastro-esofágico (RGE). A perturbação respiratória obstrutiva do sono pode apresentar-se com uma gravidade em crescendo que vai desde o ressonar primário, passando pelo síndrome de resistência das vias aéreas superiores (SRVAS) e síndrome de hipoventilação obstrutiva (SHO), culminando no síndrome de apneia obstrutiva do sono (SAOS).

Ressonar é o sintoma cardinal do quadro obstrutivo respiratório, e consiste no ruído resultante da vibração da orofaringe decorrente da turbulência do fluxo aéreo na presença do aumento da resistência na via aérea superior. Quando não há outros eventos respiratórios associados fala-se em ressonar primário.

No outro extremo do espectro clínico está o SAOS. Nesta situação, o aumento da resistência condiciona episódios de diminuição (hipopneias) ou ausência (apneias) do fluxo aéreo, havendo esforço respiratório e hipoxémia e/ou hipercapnia. Os episódios terminam em microdespertares, em 
que o aumento do tónus dos músculos dilatadores da faringe permite o restabelecimento do fluxo aéreo. Durante a noite, repetem-se as hipopneias/ apneias e microdespertares condicionando fragmentação do sono.

No SRVAS, o aumento da resistência ao fluxo aéreo condiciona esforço respiratório e microdespertares, sem que haja apneias, hipopneias, hipoxémia ou hipercapnia. No SHO, existe uma obstrução parcial do fluxo de ar, com esforço respiratório, sem apneias ou hipopneias, mas com hipercapnia.

O SAOS, o SRVAS e o SHO, quadro 4, podem levar a complicações neurocomportamentais (sonolência diurna ou hiperatividade em crianças mais pequenas, problemas de comportamento ou dificuldades de aprendizagem), metabólicas (síndrome metabólico) ou cardiovasculares (hipertensão arterial, hipertensão pulmonar ou eventualmente cor pulmonale). Em crianças pequenas, pode também existir má progressão ponderal, relacionada com o aumento do consumo energético decorrente do esforço respiratório, com a diminuição do apetite e com alterações na produção do factor de crescimento - insuline-like growth factor.

O exame objetivo pode ser normal, nomeadamente se a criança for observada durante o dia. Se a causa for a hipertrofia adenoamigdalina, a criança apresenta habitualmente fácies adenoideu

\begin{tabular}{|l|l|l|}
\hline Lactente & Idade pré-escolar e escolar & Adolescente \\
\hline Ressonar & Ressonar & Ressonar \\
Apneia e estertor & Apneia e estertor & Apneia e estertor \\
Sono agitado & Sono agitado & Sono agitado \\
Despertares frequentes & Despertares frequentes & Despertares frequentes \\
Posturas bizarras & Posturas bizarras & Cefaleias matinais \\
Esforço respiratório & Parassónias & Cansaço \\
Sudorese & Enurese noturna & Sonolência diurna \\
Estridor & Respiração de predomínio oral & Dificuldades escolares \\
Má progressão ponderal & Voz hiponasalada & Compromisso cardiovascular \\
Irritabilidade & Agravamento com as infeções & \\
Agravamento com as & respiratórias superiores & \\
infeções respiratórias & Cefaleias matinais & \\
superiores & Hiperatividade & \\
& Défice de atenção & \\
& Comportamentos de oposição & \\
& Dificuldades escolares & \\
\hline
\end{tabular}

Quadro 4. Manifestações clínicas do SAOS, SRVAS e SHO em diferentes grupos etários. 
com respiração de predomínio oral, palato alto e ogivado e amígdalas hipertrofiadas. A avaliação da morfologia facial é fundamental, devendo ser procurados dismorfismos faciais minor (micro/ retrognatia, hipoplasia do andar médio da face, desvio do septo nasal) ou sinais de patologia alérgica como a prega nasal ou a hipertrofia dos cornetos nasais.

Se a clínica for típica e ao exame objetivo forem evidentes sinais de hipertrofia adenoamigdalina, o diagnóstico do SAOS é clínico. Noutras circunstâncias, pode ser necessário recorrer ao estudo poligráfico do sono. Este exame é realizado durante o sono noturno e consiste no registo, análise e interpretação de diferentes variáveis neurofisiológicas, cardio-respiratórias e comportamentais durante o sono. Durante o estudo é possível identificar esforço respiratório, apneias, hipopneias, hipoxémia, hipercapnia ou fragmentação do sono.

O tratamento depende da causa subjacente. Como a hipertrofia adenoamigdalina é a principal causa, a abordagem terapêutica mais frequente é a adenoamigdalectomia. A redução do peso, o tratamento da rinite alérgica ou do RGE podem também estar indicados. Em alguns casos pode ser necessário recorrer à ventilação não invasiva.

\section{Distúrbios do movimento}

relacionados com o sono

O síndrome de pernas inquietas é um distúrbio neurológico em que ocorrem sensações desconfortáveis nos membros inferiores acompanhadas por urgência, praticamente irresistível, em mexer as pernas. Estes sintomas agravam-se à noite e com a inatividade e aliviam com o movimento. O reconhecimento desta entidade em idade pediátrica é recente mas estima-se que possa afetar cerca de $2 \%$ das crianças/adolescentes a partir dos oito anos. Nestas idades, o diagnóstico é dificultado pela descrição pouco clara dos sintomas, podendo as crianças referir dor ou haver apenas resistência em ir para a cama, insónia inicial ou sono agitado. A história familiar é frequentemente positiva e o fator de risco mais comumente associado é a diminuição das reservas de ferro. Se a ferritina for inferior a $50 \mathrm{ng} / \mathrm{ml}$, está indicado a administração de ferro (6 mg/kg/dia) durante seis meses.

\section{Os distúrbios rítmicos do movimento}

caraterizam-se pela ocorrência de movimentos estereotipados, rítmicos e repetitivos da cabeça (headbanging ou headrolling) ou do corpo (bodyrocking) ao adormecer e/ou durante os microdespertares do sono. Estes movimentos são um mecanismo de auto-adormecimento que, habitualmente, desaparece com o crescimento (90\% regride até aos quatro anos). Deve ser explicado aos pais a sua benignidade, recomendadas medidas de higiene do sono e de segurança.

O bruxismo ou "ranger" dos doentes é uma entidade que, com frequência, preocupa os pais. Consiste em movimentos repetitivos involuntários e não funcionais, que habitualmente desaparecem com a erupção da dentição definitiva. A sua fisiopatologia não é completamente conhecida, descrevendo-se fatores de risco como má oclusão dentária, rinite alérgica, ansiedade, paralisia cerebral ou história familiar positiva. Se ocorrer frequentemente pode causar erosão dentária, dores faciais ou na articulação temporomandibular, cefaleias e eventualmente sintomas diurnos 
relacionados com má qualidade do sono. Nestes casos a criança/adolescente deve ser referenciada para tratamento dentário.

\subsection{FACTOS A RETER}

A higiene do sono é fundamental e deve ser promovida desde o período neonatal.

A avaliação do sono faz parte das consultas de vigilância de saúde infantil e juvenil.

As parassónias são situações benignas e transitórias, sendo fundamental a tranquilização dos pais e a instituição de medidas de higiene de sono.

A insónia comportamental da infância pode causar resistência em ir dormir, dificuldade em adormecer e/ou os múltiplos acordares noturnos; medidas de higiene de sono e estratégias de terapia comportamental adequadas à criança e à família são fundamentais.

A hipersónia verdadeira é rara; as principais causas de sonolência excessiva diurna estão relacionadas com privação ou perturbação do sono noturno.
O síndrome de pernas inquietas pode ocorrer em crianças/adolescentes e cursar com queixas de difícil caracterização nos membros inferiores, insónia inicial e sono agitado.

Os distúrbios rítmicos do movimento são situações benignas e desaparecem com o crescimento.

A hiperatividade pode ser uma manifestação de défice de sono na criança mais pequena e, por outro lado, cerca de um quarto das crianças com esta perturbação tem problemas de sono.

Ressonar não é normal; a sua investigação etiológica e abordagem terapêutica precoce são fundamentais.

A criança com síndrome de apneia obstrutiva do sono grave pode ter uma observação normal durante o dia.

A perturbação respiratória do sono na infância pode constituir um fator de risco cardiovascular para a vida adulta.

A presença de atraso de crescimento inexplicado, alterações do comportamento/hiperatividade, dificuldades de aprendizagem/concentração devem evocar a presença de um problema de sono. 